Vol. 11, No. 38, January, 2016, 53-58

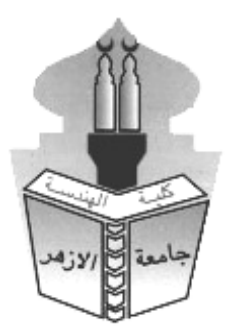

\title{
THE EFFECTS OF (RAP) ON THE LABORATORY PERFORMANCES OF HOT MIX ASPHALTS
}

\author{
Azzam A. Alkhalil ${ }^{1}$, Laila S. Radwan ${ }^{2}$ and Mohamed R. Elmitiny ${ }^{2}$ \\ ${ }^{1}$ M.Sc. in Civil Engineering (2010) - Cairo University - Egypt \\ ${ }^{2}$ Highway and Traffic, Eng., Public Works Department, Faculty of Eng.Cairo University
}

\begin{abstract}
The use of reclaimed asphalt pavement (RAP) in flexible pavement surface layer has been a major sensitive issue in the construction industry. Due to limited space available in landfills, the amount of high quality virgin aggregate declines, and the high price of oil, the use of RAP in new asphalt concrete mixtures has become very attractive. This research has been conducted to study the laboratory performances of HMA mixture containing RAP, in which Marshall properties and resilient modulus characteristic were evaluated [4,6,7]. A Marshall mix design mixture containing $0 \%$ RAP with binder (60/70) was used as the control mixture for evaluating properties of mixtures containing 25\% and 40\% RAP. Marshall tests and Indirect Tensile Modulus (Resilient Modulus) were performed on samples of the three mixes. Comparing the results of the conducted tests indicated that the use of RAP in Hot Mix Asphalt (HMA) was advantageous in all properties measured. The mix containing RAP showed reduction in Marshall Stability, indirect tensile value, and Resilient Modulus, and the higher the temperature the lower of resilient modulus values, but the results are acceptable by Egyptian code specifications. Therefore, it is preferred to use mixes containing RAP in highways with studied proportions.

(c) 2014 Faculty of Engineering, Al-Azhar University, Cairo, Egypt. All rights reserved.
\end{abstract}

Keywords: HMA, RAP, Marshall Stability, indirect tensile test and Resilient Modulus.

\section{INTRODUCTION}

With increased demand and limited aggregate and binder supply, hot mix asphalt (HMA) producers discovered that reclaimed asphalt pavement (RAP) is a valuable component in HMA. As a result, there has been renewed interest in increasing the amount of RAP used in HMA [5, 12]. While a number of factors drive the use of RAP in asphalt pavements, the two primary factors are economic savings and environmental benefits. RAP is a useful alternative to virgin materials because it reduces the use of virgin aggregate and the amount of virgin asphalt binder required in the production of HMA. Using RAP greatly reduces the amount of construction debris going into landfills, and it does not deplete nonrenewable natural resources such as virgin aggregate and asphalt binder. Ultimately, recycling asphalt creates a cycle of reuse that optimizes the use of natural resources and sustains the asphalt pavement industry. More widespread use of higher amounts of RAP in asphalt mixtures requires support from State transportation departments and the HMA industry. State transportation departments have expressed concern over the lack of guidance on the use of high percentages of RAP (high RAP) mixtures, as well as the lack of information on their performance. As a result, there is a need for national guidance on best practices when using RAP and documented information about longterm performance of high RAP pavements $[5,7,10]$. 
The intent of this paper is to provide state-of-the-practice information on including higher amounts of RAP in asphalt mixtures. The states of the practice for RAP use across the United States, as well as common challenges for increasing the use of RAP, are identified. Best practices applicable for the use of RAP are presented to identify general parameters that must be considered when developing specifications and to provide information on available resources and best practices for sourcing, processing, stockpiling, testing, designing, evaluating, producing, and placing high RAP mixtures, as well as practices to attain the best performance for high RAP mixtures $[1,13]$. The objective of this study is to investigate the suitability of using the local materials and the milled asphalt concrete waste in producing RAP that suits Egypt environmental and loading conditions.

\section{Materials and methods}

This study was conducted based on the methodology depicted in Figure (1). The first task of the study comprised the materials' characterization including aggregates, asphalts, and RAP (i.e., gradation and estimation of the asphalt content in the RAP). Subsequently, by applying the Marshall mix-design method, the percentage of asphalt to be added to the new HMA mixtures was determined. The objective of the mix design was to obtain a mixture exhibiting balanced conditions in terms of stability, flow, density, and total air voids content. Then, laboratory specimens were produced based on the aggregate gradation specified for the (3D) gradation in

Egyptian specifications for HMA mixture and using (60/70) penetration asphalts. These specimens were compacted at 75 blows per face using the Marshall compactor. The study concluded by conducting the mechanical characterization of the HMA mixtures through the indirect tensile test and resilient modulus test to measure some properties of the three hot asphalt concrete mixes, and then to compare their performance. The proceeding text provides detailed description of the adapted procedure [11].

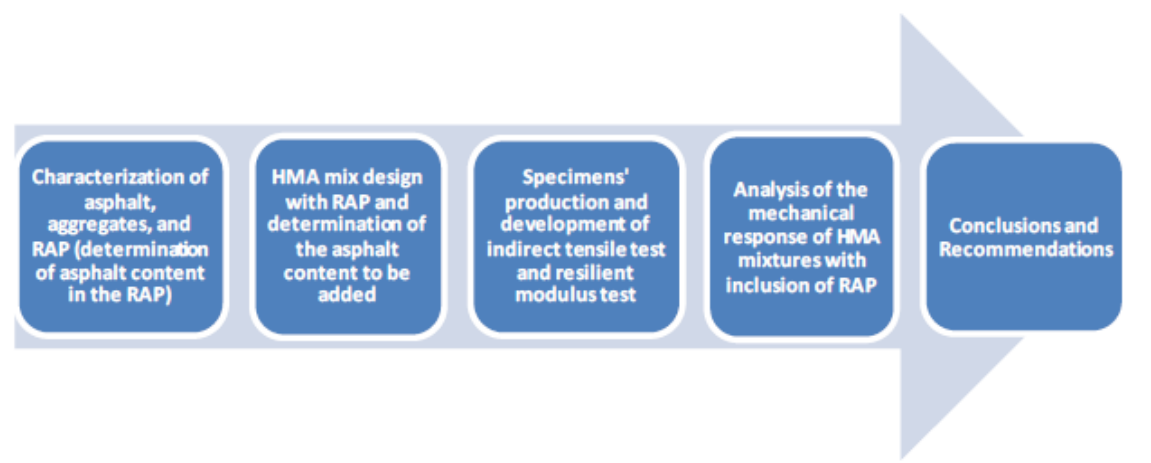

Fig. 1. Research Methodology Conducted For The Use Of RAP In Asphalt Mixes [8].

The RAP for this study was obtained by processing millings from of maintenance operations carried out by the General Authority for Roads \& Bridges and Land Transport (GARBLT) on the Alexandria - Cairo desert Road at Kilometer 90 approx. Representative samples of reasonable sizes from the site were selected following the (ASTM C-702) test procedure. This procedure is crucial to reduce bias due to unforeseen factors that would affect measurements. In order to estimate the amount of asphalt in the RAP material, extraction test (ASTM D2172-95) was performed followed by sieve analysis of the clean aggregate. The asphalt content of RAP was found to be $(3.75 \%)$. Table (1) presents the results on the characterization of the RAP and fresh aggregates used and Figure (1) shows the gradation of RAP aggregate and specifications limit. It can be noticed that RAP aggregate gradation is finer than the median recommended gradation $(3 \mathrm{D})[2,3]$.

This is mainly due to the crushing of the aggregates during the milling process, in addition to the aggregate wear that occurs during mixing, compaction and traffic serving of the asphalt concrete mix. Specific gravity and absorption of the RAP aggregate were calculated according to ASTM C127-88 (for coarse aggregates) and ASTM C128-97 (for fine aggregates) test procedures [2,3]. 
Table1. Los Angeles Abrasion, Specific Gravity, and Water Absorption for the Different Aggregate Fractions

\begin{tabular}{|c|c|c|c|c|}
\hline \hline $\begin{array}{c}\text { Aggregate Type } \\
\text { and Designation }\end{array}$ & Los Angeles \% & $\begin{array}{c}\text { Bulk Specific } \\
\text { Gravity }\end{array}$ & $\begin{array}{c}\text { Apparent Specific } \\
\text { Gravity }\end{array}$ & $\begin{array}{c}\text { Water } \\
\text { Absorption \% }\end{array}$ \\
\hline \hline $\begin{array}{c}\text { Dolomite (AGG. } \\
\text { 2) }\end{array}$ & 26.20 & 2.587 & 2.674 & 1.20 \\
\hline $\begin{array}{c}\text { Dolomite (AGG. } \\
\text { 1) }\end{array}$ & 24.26 & 2.605 & 2.683 & 1.40 \\
\hline $\begin{array}{c}\text { Manufactured } \\
\text { Sand (MS) }\end{array}$ & -- & 2.744 & 2.774 & 0.40 \\
\hline Stone Filler & --- & 2.726 & 3.024 & 3.60 \\
\hline RAP Aggregates & 31.55 & 2.621 & 2.70 & 1.38 \\
\hline \hline
\end{tabular}

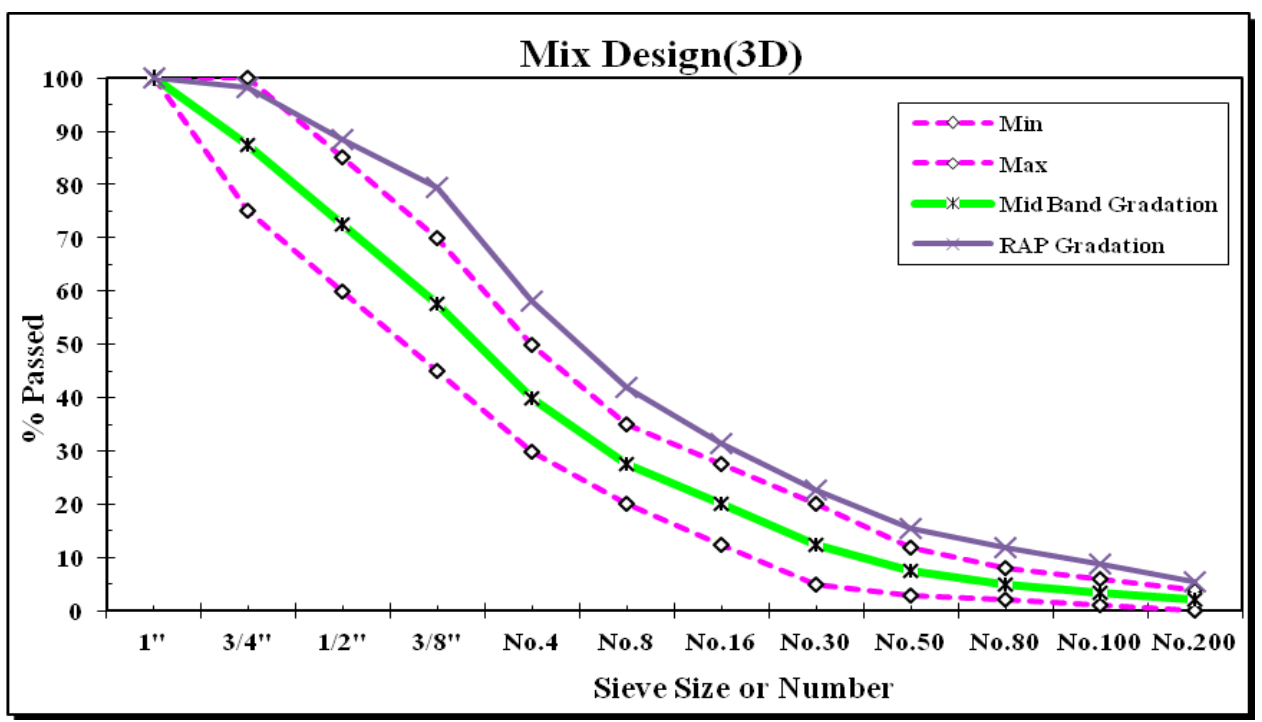

Fig.1. Egyptian specified gradation limits, median gradation, and RAP aggregate gradation

To determine the percentage of asphalt to be added to the control mixture (A) and HMA mixtures produced with RAP (B \& C), Marshall compacted specimens with addition of asphalt were prepared. Figure (3) shows typical results of stability, flow, and density of the corresponding specimens determined for the three HMA mixtures. From the Marshall test results (i.e., stability, flow, density, and total air voids content); the percentage of neat asphalt to be added was determined as $5.65 \%$ for mix (A), $5.45 \%$ for mix (B), and $5.50 \%$ for mix (C).

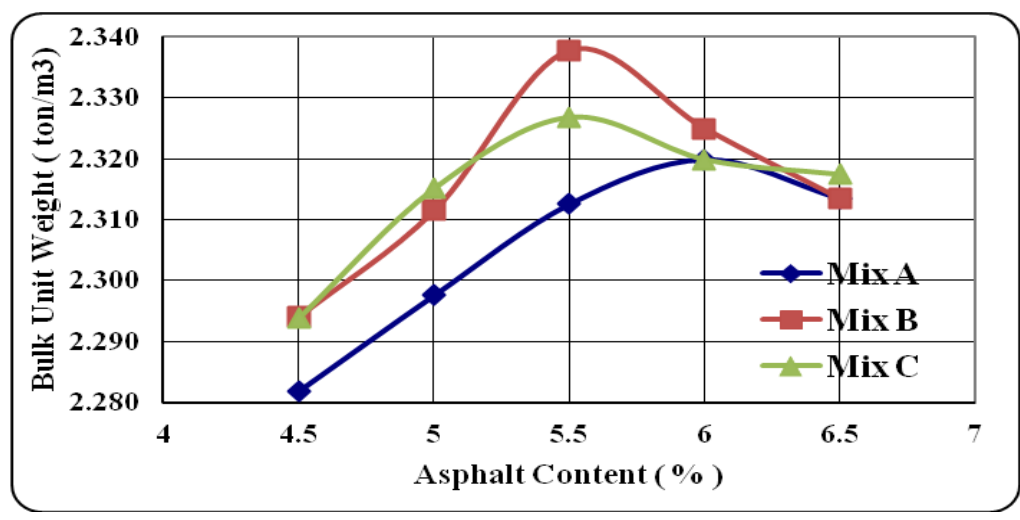



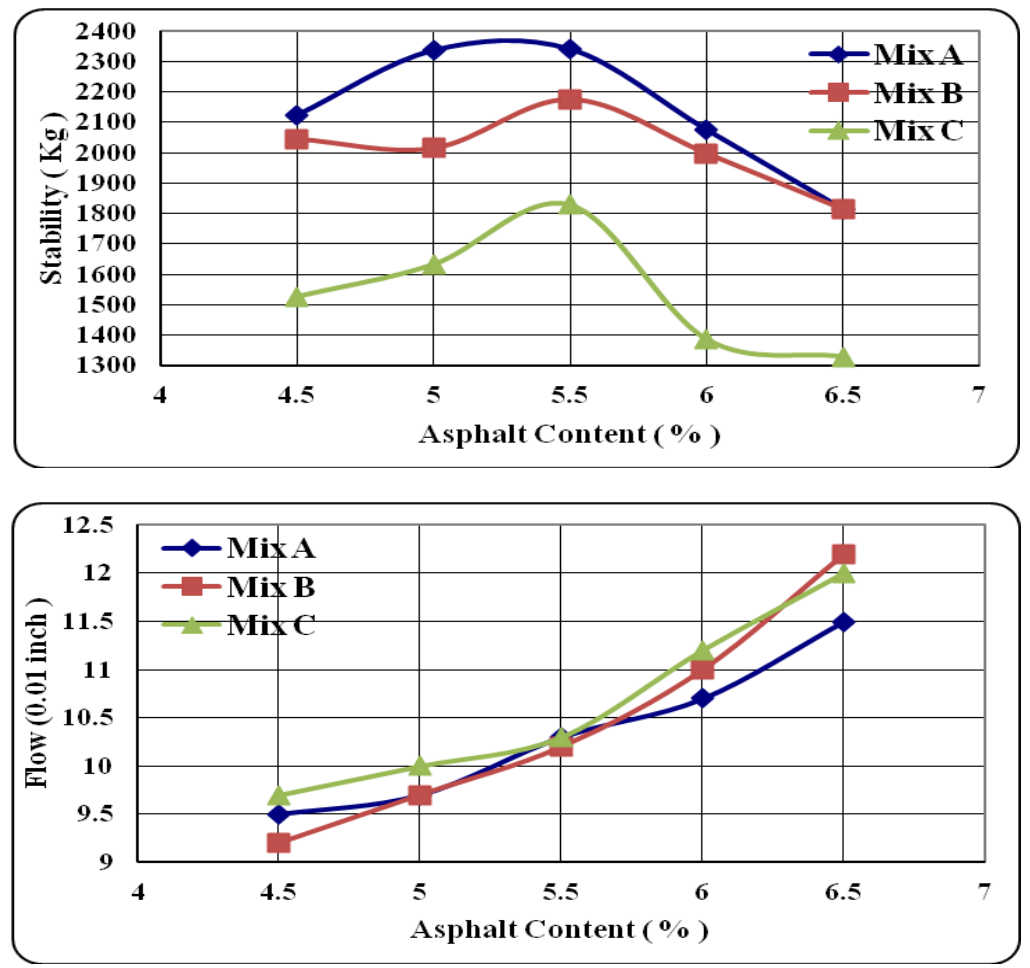

Fig. 2. density, Stability, and flow Charts for HMA mixtures fabricated with RAP inclusion

The mechanical response of the HMA mixtures was then assessed based on the indirect tensile test and resilient modulus test conducted on specimens.

\section{RESULTS AND DISCUSSION}

This section presents the mechanical characterization results for the three HMA mixtures analyzed. These results include values of ITS for the specimens tested at wet conditions, and resilient modulus for the specimens fabricated with the (3D) gradation, asphalt type (60/70), and different RAP replacement proportions. Figure (3) shows the ITS values for the specimens with different RAP replacements. Regardless of the asphalt type, the lowest ITS corresponds to the HMA mixture fabricated with the $40 \%$ RAP replacement, while the higher strength was found for the control mix. The differences reported between the HMA mixtures fabricated with the $25 \%$ RAP replacement and the $40 \%$ RAP replacements are substantial and denote that the aggregate fraction can be critical to ensure the HMA mixture response.

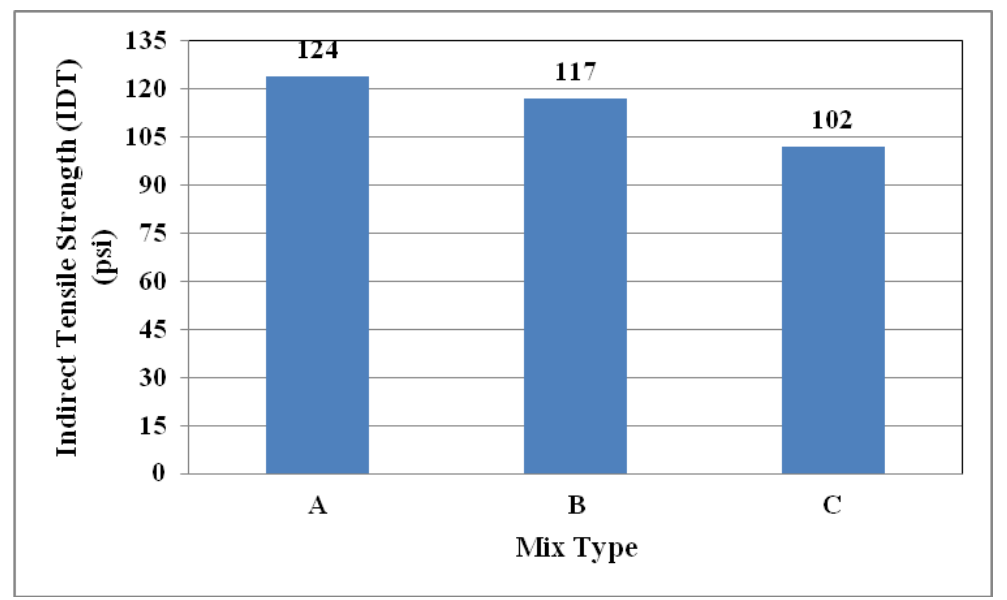

Fig. 3. Values of Indirect Tensile Strength (ITS) for Specimens Tested in Wet Condition 
The effect of the RAP fraction on the mixture strength can be related to the following aspects: (i) lack of friction between the RAP aggregates due to presence of the former asphalt binder and (ii) the existence of free asphalt binder in the mixture due to the lack of air voids in the RAP fraction (i.e., inadequate size particle distribution in the RAP fraction).

The second fundamental engineering property used to evaluate the HMA response is the resilient modulus, which is obtained from the indirect tensile modulus test conducted using the universal testing machine. As mentioned before, the test was conducted under three different temperatures and at three different loading times representing different traffic volumes/vehicle speeds [9].

Figure (4) shows the resilient modulus values for specimens produced, respectively, with the 60/70 asphalt. These specimens were tested in dry condition. As depicted, the HMA mixtures produced with $0 \%$ RAP show the highest stiffness values, regardless the test frequency and asphalt type. On the other hand, the HMA mixture produced with the 40\% RAP replacement exhibits the lowest modulus values. Nevertheless, when comparing the mixtures fabricated with partial replacement of aggregates by RAP, higher values are reported for the control HMA mixture.

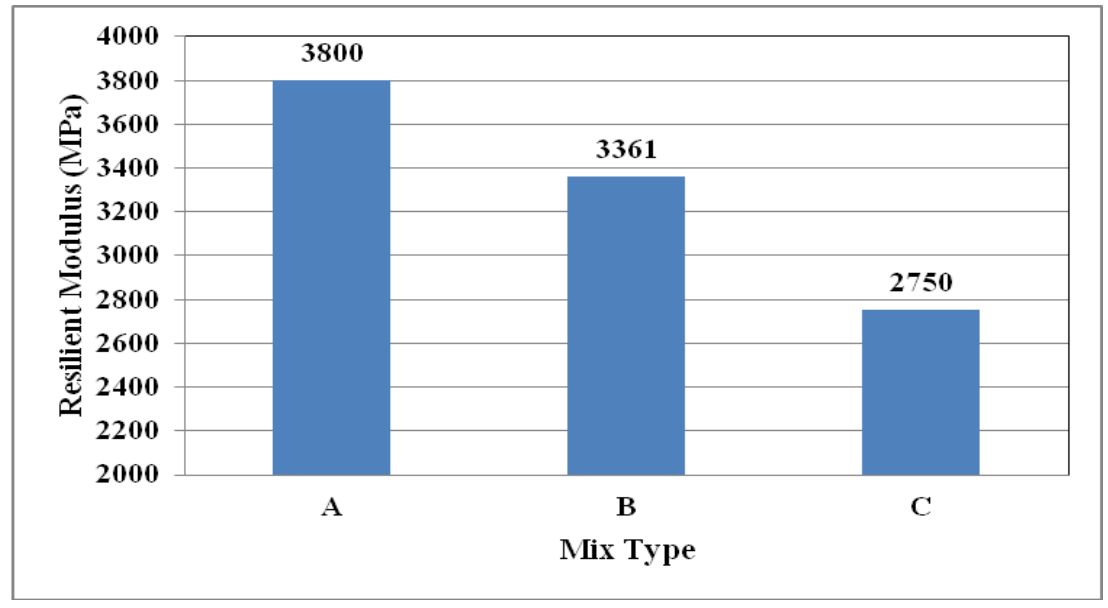

Fig. 4. RAP Proportion Effect on Resilient Modulus (Mr)

The temperature effect on resilient modulus is studied for three different mixes. Figure (5) summarize the temperature effect on the three studied mixes.

It is clear from Figures (5) that the resilient modulus decreases significantly up to about $79 \%$ and $75 \%$ with just an increase of $15^{\circ} \mathrm{C}$ (from $25^{\circ} \mathrm{C}$ to $40^{\circ} \mathrm{C}$ ) and $20^{\circ} \mathrm{C}$ (from $5^{\circ} \mathrm{C}$ to $25^{\circ} \mathrm{C}$ ) in temperature, respectively. Also, it can be observed that resilient modulus ( $\mathrm{Mr}$ ) decreases drastically with the increase in temperature and the rate of $\mathrm{Mr}$ decrease increases with increasing the values of temperatures.

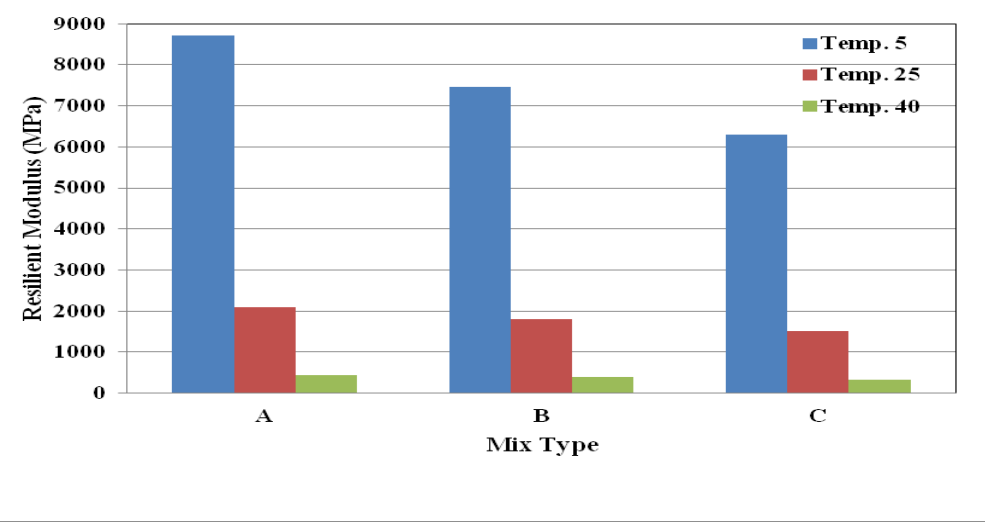

Fig. (5): Variation of Resilient Modulus with Temperature for Different HMA Mixes 


\section{CONCLUSIONS}

This paper presents an evaluation of the effect of conducting partial replacements of aggregates by RAP to fabricate HMA mixtures. Hence, the research focused on evaluating the mechanical response of the HMA mixtures produced with inclusion of RAP. This evaluation was conducted in terms of the indirect tensile strength (ITS) in wet-condition, and resilient modulus of HMA mixtures. Based on the laboratory results and corresponding analysis conducted, the next conclusions are offered:

1. The highest ITS and resilient modulus values were obtained for laboratory specimens fabricated with $0 \%$ replacement of granular material by RAP, independently of the asphalt type used in the HMA mixture. These results show the potential effect of the aged asphalt (stiffer asphalt binder as compared to that used to fabricate the new mixtures) contained in the RAP on the mechanical response of the recycled mixtures.

2. Replacement by $40 \%$ RAP of the granular material, exhibited the most unfavorable conditions, regardless of the testing condition, asphalt type, and testing carried out (i.e., ITS and resilient moduli). Therefore, replacement by RAP of the aggregate fraction aforementioned was identified as critical for the mechanical response of the HMA mixtures evaluated. This aspect can be related to the lack of friction between the RAP aggregates and/or the existence of free asphalt binder in the mixture due to the lack of air voids in the RAP fraction.

3. Higher ITS and resilient modulus values were reported for control HMA mixture fabricated with the 60/70 asphalt.

4. Increasing temperature from $\left(5\right.$ to $\left.40{ }^{\circ} \mathrm{C}\right)$ results in significant decrease in resilient modulus values.

\section{REFERENCES}

1. Abd El-Gawad, 2006,"Evaluation of the Performance of Hot Mix Asphalt Concrete Mixture with 40/50 and 60/70 Asphalt Grades" M.Sc. thesis, Faculty of Engineering, Cairo University, Cairo, Egypt.

2. American Association of State Highway and Transportation Officials (AASHTO). 1988. Standard Specifications for Transportation Materials and Methods of Sampling and Testing, 19th Edition, Washington, D.C.

3. American Society of Testing and Materials (ASTM). 2000. Annual Book of ASTM Standards (03-04), West Conshohocken, PA.

4. Al-Qadi, I.L., Elseifi, M., and Carpenter, S. H. (2007). Reclaimed Asphalt Pavement - A Literature Review, Project Report FHWA-ICT-07-001. Illinois Center for Transportation. University of Illinois at Urbana-Champaign, Illinois.

5. ARRA 2001. Basic Asphalt Recycling Manual. Asphalt Recycling and Reclaiming Association, USA.

6. Chen, J., Wang, C. \& Huang, C. (2009). Engineering properties of bituminous mixtures blended with second reclaimed asphaltpavements (R2AP). Road Materials and Pavement Design, 10, $129-149$.

7. European standard (2004). Bituminous mixtures - test methods for hot mix asphalt. EN 12697-12: 2003-Part 12 - Determination of the water sensitivity of bituminous specimens.

8.http://www.asphaltwa.com/wapa_web/modules/02_pavement_types/02_recycled_hma.htm

9. KB de Vos, 1996, "Universal Testing Machine (UTM)", Reference Manual, Software

Platform Version 2.

10. NAPA 2007. Recycling Hot Mix Asphalt Pavements. National Asphalt Pavement Association, IS 123, Lanham, MD.

11. NCHRP 2011. A Manual for Design of Hot Mix Asphalt with Commentary. National Cooperative Highway Research Program, Report 673, Transportation Research Board.

12. Taylor, N. (1997). Life expectancy of recycled asphalt paving. Recycling of bituminous pavements (L. E. Wood, Ed.). ASTM STP 662, 3-15.

13. The Washington Asphalt Pavement Association's Asphalt Pavement Guide. 2002. Available on line at: http://www.asphaltwa.com/wapa_web/modules/02_pave ment_types/02_recycled_hma.htm, (Oct., 2007). 